Provided for non-commercial research and education use. Not for reproduction, distribution or commercial use.

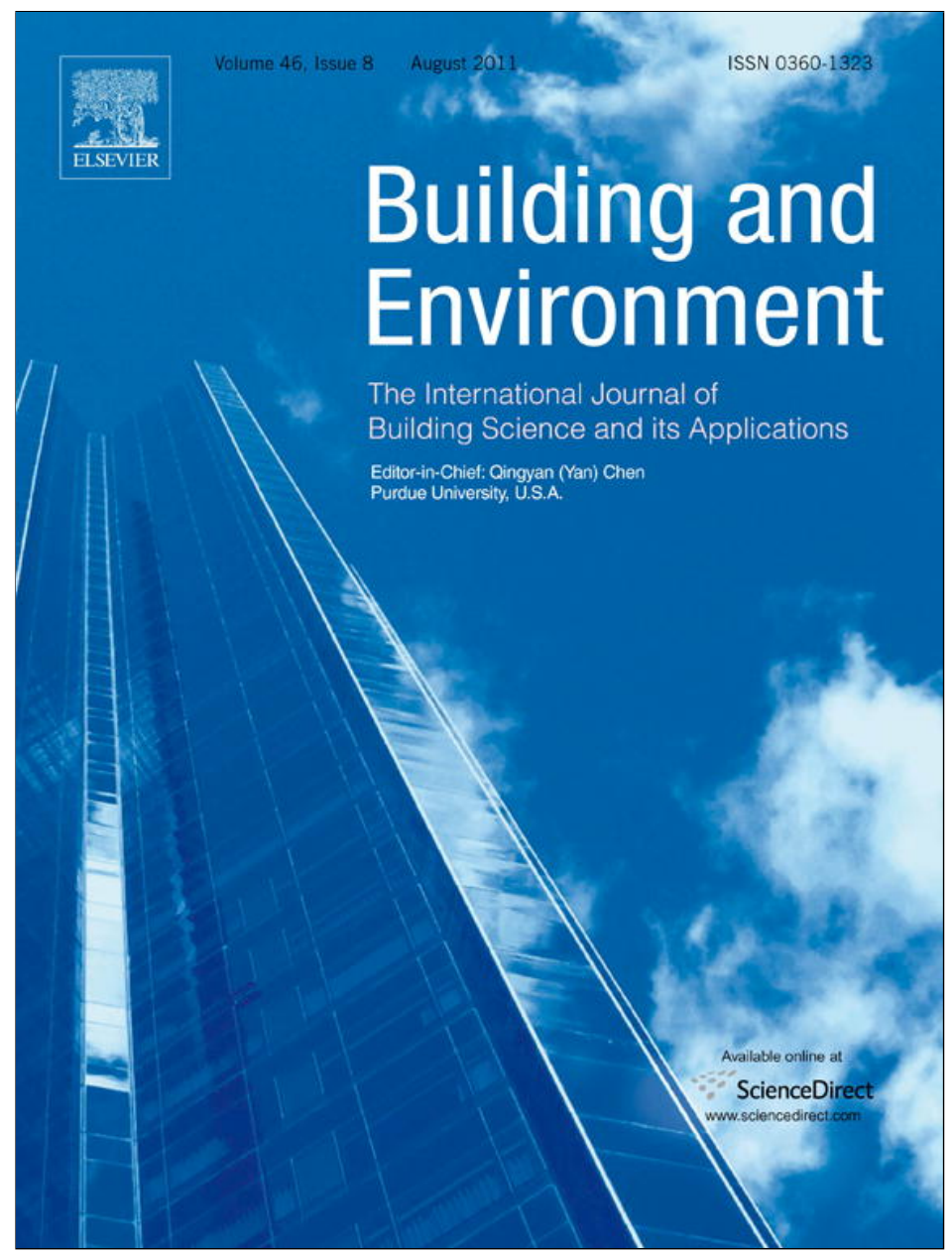

This article appeared in a journal published by Elsevier. The attached copy is furnished to the author for internal non-commercial research and education use, including for instruction at the authors institution and sharing with colleagues.

Other uses, including reproduction and distribution, or selling or licensing copies, or posting to personal, institutional or third party websites are prohibited.

In most cases authors are permitted to post their version of the article (e.g. in Word or Tex form) to their personal website or institutional repository. Authors requiring further information regarding Elsevier's archiving and manuscript policies are encouraged to visit:

http://www.elsevier.com/copyright 


\title{
Transient buoyancy-driven ventilation: Part 2. Modelling heat transfer
}

\author{
Steven D. Sandbach*, Gregory F. Lane-Serff \\ School of Mechanical, Aerospace and Civil Engineering, University of Manchester, Pariser Building, Sackville Street, Manchester M13 9PL, UK
}

\section{A R T I C L E I N F O}

\section{Article history:}

Received 4 October 2010

Received in revised form

13 January 2011

Accepted 18 January 2011

\section{Keywords:}

Buoyancy

Ventilation

Doorway

Displacement

Heat transfer

Modelling

\begin{abstract}
A B S T R A C T
A new mathematical model for buoyancy-driven ventilation [Sandbach SD, Lane-Serff GF. Transient buoyancy-driven ventilation: Part 1. Modelling advection. Building and Environment, 2011] is modified to include heat transfer at the boundaries. Heat transfers at the ceiling and floor are included, using Newton's law of cooling to model convective heat transfer between the air and the solid boundaries, Fourier's law to model conductive heat transfer through the floor and ceiling, and a linear version of the Stefan-Boltzmann law to model radiative heat transfer from the ceiling to the floor. The effectiveness of the model was assessed using experimental results obtained in a full-scale test room. In these experiments, the vertical temperature stratification was measured using an array of T-type thermocouples. Speed measurements were obtained to estimate the ventilation flow rate (for displacement ventilation) and the velocity profile across the doorway (for doorway ventilation). Buoyancy was introduced using a twin-hob $(\sim 2.35 \mathrm{~kW})$ heat source, and in most cases a diffuse two-layer temperature stratification developed. The results from these experiments are compared with the model and existing adiabatic models. Our results indicate that the effect of heat transfer at the boundaries on the final stratification is significant and should not be ignored. Furthermore, direct comparisons between the measured and modelled results are in general very good.
\end{abstract}

(c) 2011 Elsevier Ltd. All rights reserved.

\section{Introduction}

In an accompanying paper [1], a new mathematical model for buoyancy-driven ventilation was proposed. The filling with buoyant fluid of a ventilated space due to a localised source of buoyancy was considered. Both doorway and displacement ventilation were considered where the temporal stratification that develops is calculated using a modified version of Germeles' [2] filling-box model. The model was developed and validated using results obtained from a series of reduced-scale salt bath experiments. In these experiments, salinity differences are used to drive the flow. Consequently, there is no buoyancy transfer modelling heat transfers at the boundaries.

For thermally driven flows, this heat transfer leads to conductive heat losses and secondary heat transfers (convective and radiative) that redistribute the energy in the room. These heat transfers play a role in determining the final temperature distribution and in most of the full-scale experiments of displacement ventilation [3-7], a largely linear temperature profile was observed. There is, however, a full-scale experimental investigation of forced

\footnotetext{
* Corresponding author. College of Life and Environmental Sciences, University of Exeter, Amory Building, Rennes Drive, Exeter EX4 4RJ, UK.

E-mail address: s.sandbach@exeter.ac.uk (S.D. Sandbach).
}

displacement ventilation, where a two-layer temperature and concentration stratification was measured [8]. For this particular case, significant effort was invested in ensuring a diffuse inlet to prevent the ventilation flux from significantly modifying the flow in the room.

In this paper, the advection model described in part 1 [1] is developed further to incorporate heat transfers at the boundaries. The effectiveness of the model is assessed using experimental results obtained in a full-scale test room. These experiments are described in the following section, with the heat-transfer calculation detailed in Section 3. Results obtained using the new mathematical model are then compared with both experimental results and existing adiabatic mathematical models $[9,10]$ in Section 4 and finally some conclusions are drawn in Section 5.

\section{Experiments}

The experiments were conducted in a test room measuring $2.78 \mathrm{~m}$ high by $7.46 \mathrm{~m}$ wide by $5.59 \mathrm{~m}$ deep (see Fig. 1 ). The test room was constructed primarily from plasterboard and was located in a laboratory approximately 7.5 times larger in volume. The walls were constructed from two sections of plasterboard $15 \mathrm{~mm}$ thick, separated by an air gap of $54 \mathrm{~mm}$. The chamber floor was located above the laboratory floor by $200 \mathrm{~mm}$ and constructed from wood 


\author{
Nomenclature \\ Dimensional parameters \\ A cross sectional area of the ceiling/floor $\left(\mathrm{m}^{2}\right)$ \\ $A_{\mathrm{u}}$ and $A_{\mathrm{l}}$ upper and lower ventilation opening areas $\left(\mathrm{m}^{2}\right)$ \\ $B_{0}\left(\approx 2.8 \times 10^{-5} E_{0}\right)$ source buoyancy flux $\left(\mathrm{m}^{4} \mathrm{~s}^{-3}\right)$ \\ $D_{\mathrm{h}} \quad$ hydraulic diameter $(\mathrm{m})$ \\ $E_{0} \quad$ source power $(\mathrm{kW})$ \\ g gravitational acceleration $\left(\mathrm{m} \mathrm{s}^{-2}\right)$ \\ $g^{\prime} \quad$ reduced gravitational acceleration due to density \\ differences $\left(\mathrm{m} \mathrm{s}^{-2}\right)$ \\ $H \quad$ height measured above the floor (m) \\ $H_{\mathrm{r}} \quad$ height of the room (m) \\ $H_{\mathrm{r}, \text { eff }}$ effective height of the room, this is the rise height of \\ the plume measured from the hypothetical point \\ source to the ceiling $(\mathrm{m})$ \\ $L_{\mathrm{f}}$ and $L_{\mathrm{c}}$ floor and ceiling depth $(\mathrm{m})$ \\ $Q_{\mathrm{v}} \quad$ ventilation flow rate $\left(\mathrm{m}^{3} \mathrm{~s}^{-1}\right)$ \\ $t \quad$ time (s) \\ Z vertical height above the plume hypothetical point \\ source $(\mathrm{m})$ \\ $\rho \quad$ density $\left(\mathrm{kg} \mathrm{m}^{-3}\right)$ \\ $m \quad$ mass $(\mathrm{kg})$ \\ $c_{\mathrm{p}} \quad$ specific heat capacity $\left(\mathrm{J} \mathrm{kg}^{-1} \mathrm{~K}^{-1}\right)$ \\ $T$ temperature (K) \\ $g_{s}^{\prime}, Q_{s}, t_{s}$ and $Z_{s}$ scales used to non-dimensionalise reduced \\ gravity, volume flow rate, time and vertical lengths \\ (see in Eqs. (2))
}

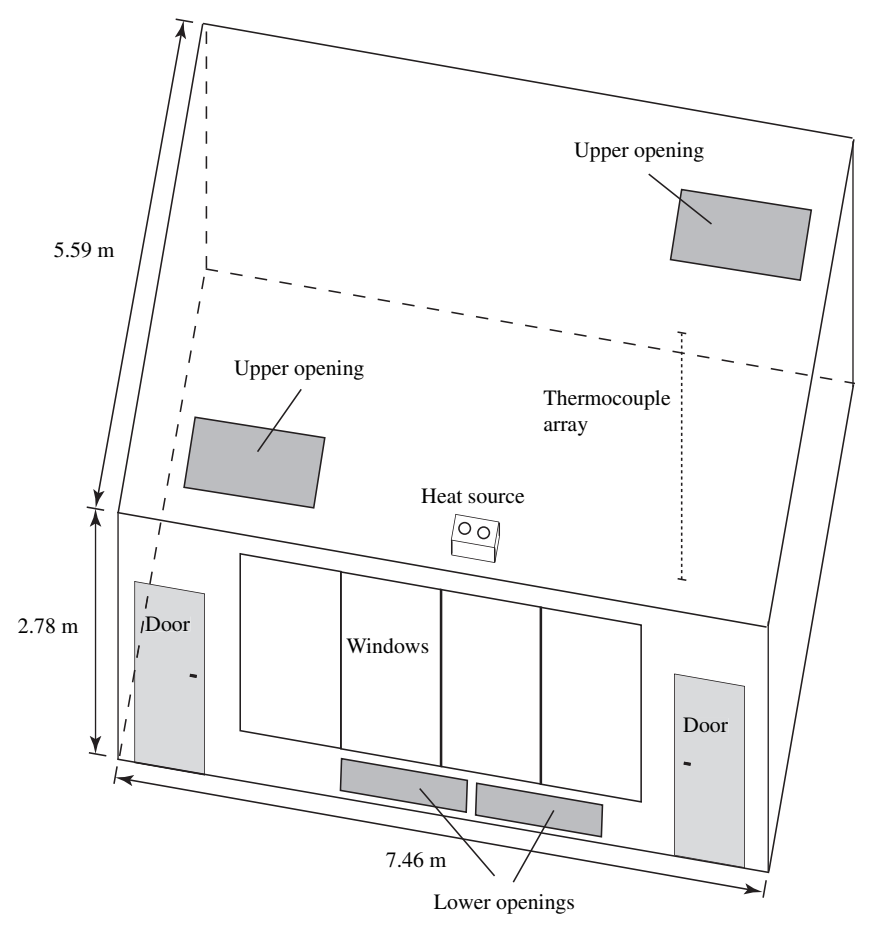

Fig. 1. Three-dimensional representation of the test room.
Non-dimensional parameters

$a^{*}\left(=\frac{C_{\mathrm{d}}}{H_{\mathrm{r}, \text { eff }}} \frac{\sqrt{2} A_{\mathrm{u}} A_{\mathrm{l}}}{\sqrt{A_{\mathrm{u}}^{2}+A_{\mathrm{u}}^{2}}}\right)$ effective opening area normalised by the effective height of the room

$q\left(=Q / Q_{s}\right)$ dimensionless volume flow rate (scale defined in Eq. (1))

$\delta\left(=g^{\prime} \mid g_{s}^{\prime}\right)$ dimensionless reduced gravity (scale defined in Eq. (1))

$\tau\left(=t / t_{\mathrm{s}}\right)$ dimensionless time (scale defined in Eq. (1))

$z\left(=Z \mid Z_{\mathrm{s}}\right)$ dimensionless vertical height above the plume hypothetical point source $(\mathrm{m})$

Heat-transfer coefficients and non-dimensional parameters

$k \quad$ conductivity $\left(\mathrm{W} \mathrm{m}^{-1} \mathrm{~K}^{-1}\right)$

$\alpha_{\text {conv }} \quad$ convective heat-transfer coefficient $\left(\mathrm{W} \mathrm{m}^{-1} \mathrm{~K}^{-1}\right)$

$\alpha_{\mathrm{rad}} \quad$ radiative heat-transfer coefficient $\left(\mathrm{W} \mathrm{m}^{-1} \mathrm{~K}^{-1}\right)$

$\widehat{\alpha}\left(=k / \rho c_{\mathrm{p}}\right)$ thermal diffusivity $\left(\mathrm{m}^{2} \mathrm{~s}^{-1}\right)$

$B i\left(=\alpha_{\text {conv }} L_{s} / k\right)$ Biot number

$\widetilde{B} i\left(=\alpha_{\mathrm{rad}} L_{\mathrm{s}} / k\right)$ a form of the Biot number based on radiative fluxes

Fo $\left(=\widehat{\alpha} \Delta t / L_{\mathrm{s}}^{2}\right)$ Fourier number

$S t\left(=\alpha_{\text {conv }} t_{\mathrm{s}} / \rho c_{\mathrm{p}} H_{\mathrm{r}, \text { eff }}\right)$ Stanton number

Constants

$C_{\mathrm{en}}\left(=4 \pi^{2 / 3} \alpha_{\mathrm{en}}^{4 / 3}\right)$ entrainment coefficient defined to simplify the scales defined in Eq. (2)

$n, n_{\mathrm{T}}$ and $n_{\mathrm{ht}}$ number of stratification layers, temperature nodes and heat-transfer time steps

$\alpha_{\text {en }} \quad$ plume entrainment constant defined as the ratio between the mean centreline velocity and the mean entrainment velocity
$100 \mathrm{~mm}$ thick and covered in carpet tiles. The chamber ceiling was constructed from single panels of plasterboard suspended from the laboratory ceiling by a $1 \mathrm{~m}$ clearance.

Two doorway openings (measuring $2.03 \mathrm{~m}$ high and $0.79 \mathrm{~m}$ wide) were located on the same wall, separated by four large window panels ( $2.0 \mathrm{~m}$ high and $1.14 \mathrm{~m}$ wide). The windows were constructed from single glass panels $7 \mathrm{~mm}$ thick. To reduce heatloss asymmetry, the windows were insulated using large plastic sheeting. The sheeting was attached to the framework on both sides of each window to effectively act like triple glazing.

High-level openings were made by removing various plasterboard panels, producing various effective opening areas. Each panel measured approximately $0.70 \mathrm{~m}^{2}$ and smaller cuts of plasterboard were used to close off part of each opening where required. Two low-level openings were constructed below the window panels, measuring $0.29 \mathrm{~m}^{2}$ and $0.355 \mathrm{~m}^{2}$ respectively. The construction was such that it was possible to shut off part or all of each opening so that various effective openings were possible up to a maximum of $0.63 \mathrm{~m}^{2}$. The material properties of the ceiling, floor and air used to calculate the results presented in Section 4 were obtained from Incropera and DeWitt [11] and are summarised in Table 1.

A twin-hob heat source nominally rated at $2.4 \mathrm{~kW}$, located on the floor at the centre of the chamber, was used to introduce buoyancy. With the heat source placed on the floor, the heating element was approximately $15 \mathrm{~cm}$ above the floor level (See Section 3.1 for discussion of effective origin of buoyant plumes rising from the heat source). The heat source was independently verified using a Watt meter and found to be $1.25 \mathrm{~kW}$ and $2.35 \mathrm{~kW}$ for a single and a twin-ring configuration respectively. 
Table 1

Material properties obtained from Incropera and DeWitt [11].

\begin{tabular}{lcll}
\hline Material & $\rho\left(\mathrm{kg} \mathrm{m}^{-3}\right)$ & $c_{\mathrm{p}}\left(\mathrm{J} \mathrm{kg}^{-1} \mathrm{~K}^{-1}\right)$ & $k\left(\mathrm{~W} \mathrm{~m}^{-1} \mathrm{~K}^{-1}\right)$ \\
\hline Ceiling & 800 & 1000 & 0.17 \\
Floor & 1000 & 1300 & 0.17 \\
Air $(T=300 \mathrm{~K})$ & 1.164 & 1007 & - \\
\hline
\end{tabular}

A series of experiments were conducted using both single and twin-ring heat-source configurations. In the doorway ventilation experiments, a single open doorway was used and in the displacement-ventilation experiments four effective opening area configurations were used (summarised in Table 2). During each experiment, temperature measurements were obtained using T-type thermocouples measuring the vertical temperature profile (28 thermocouples), the temperature across the openings ( 8 thermocouples), the temperature at the wall surfaces (20 thermocouples) and the ambient temperature outside the chamber (4 thermocouples). These thermocouples were calibrated using a single thermometer with NIST traceable standards, and the maximum error was estimated to be $\pm 0.15 \mathrm{~K}$.

Speed measurements were also obtained using a low-speed $\left(0-1 \mathrm{~m} \mathrm{~s}^{-1}\right)$ Bruël and Kjær thermal anemometer. These measurements were taken: $i$ ) at a location across the inlet that was representative of the mean inlet velocity; and ii) at various vertical locations across the doorway opening during the doorway flow experiments. In the displacement-ventilation experiments, flow measurements were obtained for the entire duration of each experiment to calculate the temporal change in ventilation flow rate. In the doorway experiments, speed measurements were obtained at various vertical heights once the flow had approximately reached steady-state (approximately $6 \mathrm{~h}$ into the experiment). In the doorway ventilation experiments, speed measurements were taken by sweeping vertically upwards, followed by a vertical sweep downwards. The results obtained from these experiments are presented in Section 4.1.

\section{Heat-transfer calculations}

For thermally driven flows there is heat transfer between the solid surfaces and the air, which leads to heat loss via conduction through the walls, ceiling and floor.

This leads to a reduction in the total buoyancy in the room and subsequently the ventilation flow rate compared to adiabatic cases. This heat transfer has two important secondary effects: $i$ ) radiative heat transfer between the upper and lower parts of the room; and ii) convective heat transport close to the walls. These secondary heat-transfer mechanisms lead to a temperature increase in the lower part of the room and a temperature reduction in the upper part of the room.

In the full-scale experiments conducted for the purpose of this work, the temperature measurements indicate that the majority of the thermal energy lost could be attributed to conductive heat transfer through the ceiling (approximately $65 \%$ of the total source input) with a negligibly small amount lost through the walls (less than 5\%). This was due to poor ceiling insulation (12 mm fibre board) and exposure to higher temperature differences (hot air

Table 2

A summary of the displacement-ventilation experimental configurations.

\begin{tabular}{lll}
\hline$A_{\mathrm{l}}\left(\mathrm{m}^{2}\right)$ & $A_{\mathrm{u}}\left(\mathrm{m}^{2}\right)$ & $a^{*}$ \\
\hline 0.290 & 0.218 & 0.019 \\
0.290 & 0.678 & 0.030 \\
0.645 & 0.678 & 0.052 \\
0.645 & 1.360 & 0.065 \\
\hline
\end{tabular}

close to the ceiling). Since most of the energy lost was exchanged with the ceiling, conductive heat transfer through the ceiling and radiative heat transfer between the ceiling and floor was modelled, ignoring the secondary convective flux close to the walls.

The heat-transfer calculation was carried out using an explicit scheme discretising the ceiling panel into $n_{\mathrm{T}}$ layers. Convective heat transfer at the ceiling and floor was calculated using Newton's law of cooling. Radiative heat transfer between the ceiling and floor was calculated using a linear version of Steffan-Boltzmann's law and the conductive heat transfer was calculated using Fourier's law.

\subsection{Modelling heat transfer}

The driving force for the flows considered here is buoyancy and in part 1 [1] of this paper, a model for buoyancy-driven ventilation was developed. This model considers the case where buoyancy forces occur due to density differences, ignoring the origin of these variations. For thermally driven flows, these variations are due to temperature differences and for the conditions considered here, the density differences are proportional to temperature differences, so we can write:

$\frac{\Delta \rho}{\rho_{\mathrm{o}}}=-\frac{\Delta T}{T_{\mathrm{o}}}$

where $\rho$ is the fluid density, $T$ is the temperature measured in $\mathrm{K}$ and the subscript ' $o$ ' denotes ambient conditions. The reduced gravity term $g^{\prime}\left(g \Delta \rho / \rho_{0}\right)$ can therefore be written in terms of temperature differences rarther than density differences.

For convenience, the advection model [1] was non-dimensionalised using the filling-box scales defined by Worster and Huppert [12], and for the purpose of integrating heat transfer into this model, the following scaling terms (from that paper) are summarised:

$$
\begin{aligned}
& z=Z_{\mathrm{s}}^{-1} Z=H_{\mathrm{r}, \mathrm{eff}}^{-1} Z, \\
& \tau=t_{\mathrm{s}}^{-1} t=C_{\mathrm{en}} H_{\mathrm{r}, \mathrm{eff}}^{2 / 3} A^{-1} B_{0}^{1 / 3} t, \\
& \delta=g_{\mathrm{s}}^{\prime-1} g^{\prime}=C_{\mathrm{en}} H_{\mathrm{r}, \mathrm{eff}}^{5 / 3} B_{0}^{-2 / 3} \delta, \\
& q=Q_{\mathrm{s}}^{-1} Q=C_{\mathrm{en}}^{-1} H_{\mathrm{r}, \mathrm{eff}}^{-5 / 3} B_{0}^{-1 / 3} Q,
\end{aligned}
$$

where $z, \tau, \delta$ and $q$ are the dimensionless vertical length, time, reduced gravity and volume flow rate and $Z_{s}, t_{s}, g_{s}^{\prime}$ and $Q_{s}$ are the vertical length, time, reduced gravity and volume flow rate scales. These scales depend on: an entrainment coefficient $C_{\mathrm{en}}(=0.321$, see [1]); the effective room height $H_{\mathrm{r}, \text { eff }}$ (see [1]); the area of the floor $A$; and the source buoyancy flux $B_{0}\left(=g E_{0} / \rho c_{\mathrm{p}} T_{0}\right)$, where $E_{0}$ is the thermal power of the source, $c_{\mathrm{p}}$ is the heat capacity of the fluid, and $g$ is the acceleration due to gravity.

In these experiments, a twin-hob heat source was located on the floor in the centre of the chamber, with the heating element approximately $15 \mathrm{~cm}$ above the floor. Mundt [13] obtained an estimate of the virtual origin based on the heat-source diameter (cited from Mundt [14]). However, the applicability of this correlation to a coiled heating element (as used in these experiments) is unknown. Therefore, for convenience, we have assumed that the plume virtual origin coincides with the floor, and so: $H_{\mathrm{r}, \mathrm{eff}}=H_{\mathrm{r}}(=2.78 \mathrm{~m})$.

Using the reduced gravity scale and Eqs. (1), the non-dimensional reduced gravity can be written in terms of temperature:

$\delta=\frac{g}{g_{\mathrm{s}}^{\prime}} \frac{T-T_{\mathrm{o}}}{T_{\mathrm{o}}}$.

This serves two purposes: $i$ ) to calculate the resulting temperate from $\delta$; and $i i$ ) to convert temperatures into 'equivalent' nondimensional reduced gravity terms for the purpose of integrating 
heat transfer into the advection model. To avoid confusion, this parameter shall be referred to as the effective buoyancy when discussing the heat-transfer calculation.

With this in mind, we now consider the energy transferred from the uppermost fluid layer to the ceiling ( $E_{\text {conv,ci, }}$, see Fig. 2 ) with the change in energy stored in that layer:

$m_{n} c_{\mathrm{p}, \mathrm{a}} \frac{\mathrm{d} \delta_{n}}{\mathrm{~d} t}=\alpha_{\mathrm{conv}, \mathrm{ci}} A\left(\delta_{\mathrm{c}, 1}-\delta_{n}\right)$

where $m_{n}$ and $c_{\mathrm{p}, \mathrm{a}}$ are the mass and heat capacity of the $n$th fluid layer, $\alpha_{\text {conv,ci }}$ is the convective heat-transfer coefficient associated with the inside ceiling surface, and $\delta_{\mathrm{c}, 1}$ is the effective buoyancy of the ceiling surface (see Eq. (4)).

We shall now consider the heat transfer through the ceiling. To do this, we split the ceiling into $n_{\mathrm{T}}$ layers defined by the ceiling surfaces and $n_{\mathrm{T}}-1$ imaginary interfaces. The thickness of the first and last layers is $0.5 \Delta Z$ where $\Delta Z=L_{c} /\left(n_{\mathrm{T}}-1\right)$ and $L_{\mathrm{C}}$ is the thickness of the ceiling. The effective buoyancy of these layers is represented by the surface effective buoyancy for each layer. The remaining layers are $\Delta Z$ thick and the effective buoyancy that represents each of these layers is located at the centre point between the respective imaginary interfaces.

For the first layer, the energy balance can be obtained by considering the convective heating from the fluid layer, conductive heat transfer, radiative heat transfer to the floor and change in energy stored in the first ceiling layer. Using a linear approximation for the radiative heat transfer (see next section for details), this is:

$$
\begin{aligned}
m_{\mathrm{c}, 1} c_{\mathrm{p}, \mathrm{c}} \frac{\mathrm{d} \delta_{\mathrm{c}, 1}}{\mathrm{~d} t}= & \alpha_{\text {conv }, \mathrm{ci}} A\left(\delta_{n}-\delta_{\mathrm{c}, 1}\right)+k_{\mathrm{c}} A \frac{\mathrm{d} \delta_{\mathrm{c}, 1}}{\mathrm{~d} Z} \\
& -\alpha_{\mathrm{rad}} A\left(\delta_{\mathrm{c}, 1}-\delta_{\mathrm{f}}\right),
\end{aligned}
$$

where $m_{\mathrm{c}, 1}$ and $\alpha_{\text {rad }}$ are the mass of the first solid ceiling layer and radiative heat-transfer coefficient respectively; $k_{\mathrm{c}}$ and $c_{\mathrm{p}, \mathrm{c}}$ are the conductive heat-transfer coefficient and specific heat capacity of the ceiling; and $\delta_{\mathrm{f}}$ is the effective buoyancy of the floor. This energy balance is schematically represented in Fig. 2, where the three terms on the right-hand side of Eq. (5) are $E_{\text {conv,ci, }}, E_{\text {cond,c1 }}$ and $E_{\text {rad }}$ respectively. The energy balance for the remaining ceiling layers up to but not including the final layer, is purely conductive and is represented using Fourier's law:

$\frac{\mathrm{d} \delta_{\mathrm{c}, j}}{\mathrm{~d} t}=\widehat{\alpha} \frac{\mathrm{d}^{2} \delta_{\mathrm{c}, j}}{\mathrm{~d} Z^{2}}$

where $\widehat{\alpha}\left(=k / \rho c_{\mathrm{p}}\right)$ is the thermal diffusivity and $\delta_{\mathrm{c}, j}$ is the effective buoyancy of the $j$ th ceiling layer. For the final ceiling layer, the heat transfer is no longer purely conductive, as it is located at a fluid-solid interface in a similar way to the first layer. The energy balance includes convective and radiative heat lost to the surroundings, conductive heat transfer and change in energy stored in the ceiling:

$m_{\mathrm{c}, n_{\mathrm{T}}} c_{\mathrm{p}, \mathrm{c}} \frac{\mathrm{d} \delta_{\mathrm{c}, n_{\mathrm{T}}}}{\mathrm{d} t}=k_{\mathrm{c}} A \frac{\mathrm{d} \delta_{\mathrm{c}, n_{\mathrm{T}}}}{\mathrm{d} Z}-\alpha_{\mathrm{cr}} A\left(\delta_{\mathrm{c}, n_{\mathrm{T}}}-\delta_{\mathrm{o}}\right)$,

where $m_{c, n T}$ is the mass of the final solid layer and $\delta_{c, n T}$ is the effective buoyancy of the $n_{\mathrm{T}}$ th ceiling layer. For the purpose of this work, the temperature outside the room is assumed to remain constant, and so the radiative and convective heat-transfer coefficients are combined $\alpha_{\text {cr }}\left(=\alpha_{\text {conv,co }}+\alpha_{\text {rad }}\right)$, where $\alpha_{\text {conv,co }}$ is the convective heat-transfer coefficient associated with the outside ceiling surface. This energy balance is schematically represented in Fig. 2, where the two terms on the right-hand side of Eq. (7) are $E_{\text {cond }, n_{\mathrm{T}}}$ and $E_{\mathrm{cr}}$ respectively.

The equations outlined so far describe how energy is transferred from the warm air inside the room to the ambient air outside the room through the ceiling. We shall now consider how the net radiative flux of thermal energy from the ceiling to the floor increases the buoyancy of the lower layer. For modelling purposes, the effective buoyancy of the outside surface of the floor is

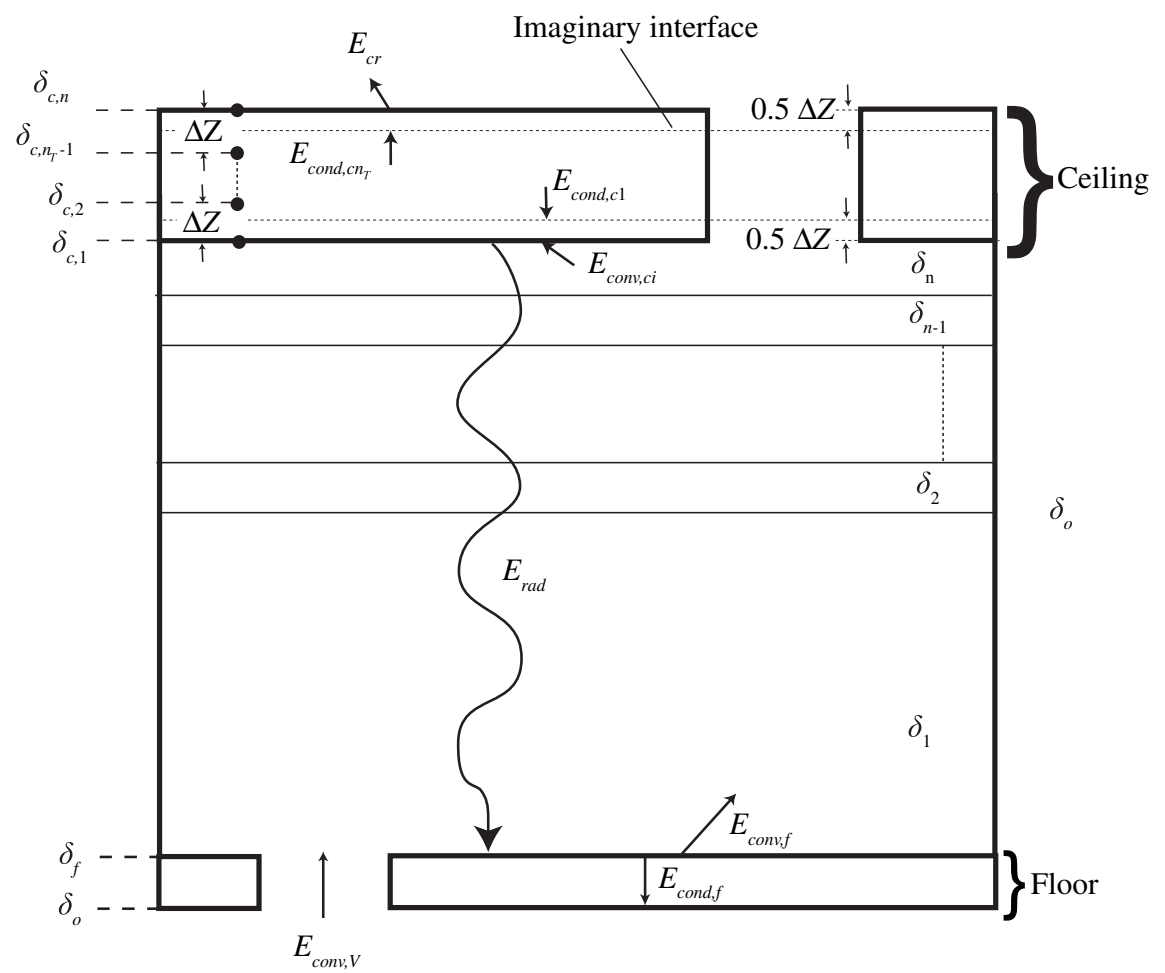

Fig. 2. Schematic representation of the model at $\tau=(n-1) \Delta \tau$ indicating the heat-transfer mechanisms at the ceiling and floor. The plume flow is omitted for clarity. 
considered to be constant and equal to the buoyancy of the air outside. We use this more simplified treatment of the floor because of the much lower heat fluxes compared to the ceiling.

Using the floor as a control volume, conservation of energy was used to obtain:

$$
\begin{aligned}
m_{\mathrm{f}} c_{\mathrm{p}, \mathrm{f}} \frac{\mathrm{d} \bar{\delta}_{\mathrm{f}}}{\mathrm{d} t}= & \alpha_{\mathrm{rad}} A\left(\delta_{\mathrm{c}, 1}-\delta_{\mathrm{f}}\right)-\alpha_{\mathrm{conv}, \mathrm{f}} A\left(\delta_{\mathrm{f}}-\delta_{1}\right) \\
& -\frac{k_{\mathrm{f}} A}{L_{\mathrm{f}}}\left(\delta_{\mathrm{f}}-\delta_{\mathrm{o}}\right),
\end{aligned}
$$

where $k_{\mathrm{f}}$ and $\alpha_{\text {conv,f }}$ are the conductive and convective heat-transfer coefficients associated with the floor, $L_{\mathrm{f}}$ is the depth of the floor, and $\bar{\delta}_{\mathrm{f}}\left(=0.5\left(\delta_{\mathrm{f}}+\delta_{\mathrm{o}}\right)\right)$ is the mean effective buoyancy of the floor. This energy balance is schematically represented in Fig. 2, where the three terms on the right-hand side of Eq. (8) are $E_{\mathrm{rad}}, E_{\mathrm{conv}, \mathrm{f}}$ and $E_{\text {cond,f }}$ respectively.

Finally, the air close to the floor is warmed by convective heat transfer from the floor and cooled by the ventilation flow. The net heat transfer increases the specific energy in the lower layer and this is modelled by balancing the convective heat transfer from the floor and the energy advected by the ventilation flow with the change in specific energy of the lower layer:

$m_{1} c_{\mathrm{p}, \mathrm{a}} \frac{\mathrm{d} \delta_{1}}{\mathrm{~d} t}=\alpha_{\mathrm{conv}, \mathrm{f}} A\left(\delta_{\mathrm{f}}-\delta_{1}\right)-\rho_{\mathrm{a}} c_{\mathrm{p}, \mathrm{a}} Q_{\mathrm{v}}\left(\delta_{1}-\delta_{\mathrm{o}}\right)$,

where $m_{1}$ is the mass of the lower fluid layer. This energy balance is schematically represented in Fig. 2, where the two terms on the right-hand side of Eq. (9) are $E_{\text {conv,f }}$ and $E_{\text {conv,V }}$ respectively. Although this set of equations was obtained by considering a displacement-ventilation flow (Fig. 2), the same set of equations is obtained for a doorway ventilation flow.

\subsection{Modelling approximations}

By considering the heat transfer schematically represented in Fig. 2, a set of $N\left(=n_{\mathrm{T}}+4\right)$ differential equations has been obtained. However, it is not possible to solve these analytically, and so a numerical solution was used with the temporal and spatial gradients approximated as:

$$
\begin{aligned}
& m \frac{\mathrm{d} \delta}{\mathrm{d} t} \approx m^{t_{\text {step }}} \frac{\delta^{p+1}-\delta^{p}}{\Delta t}, \\
& \frac{\mathrm{d} \delta}{\mathrm{d} Z} \approx \frac{\delta_{j+1}^{t_{\text {step }}}-\delta_{j}^{t_{\text {step }}}}{\Delta Z}, \\
& \frac{\mathrm{d}^{2} \delta}{\mathrm{d} Z^{2}} \approx \frac{\delta_{j+1}^{t_{\text {step }}}+\delta_{j-1}^{t_{\text {step }}}-2 \delta_{j}^{t_{\text {step }}}}{\Delta Z^{2}},
\end{aligned}
$$

where $\delta^{p+1}, \delta^{p}$ are the effective buoyancy at the new and old heattransfer time step and $\delta^{t_{\text {step }}}$ depends on the approximation applied. Using an explicit or implicit scheme, this is represented using the old $\left(t_{\text {step }}=p\right)$ or new $\left(t_{\text {step }}=p+1\right)$ time step respectively. A more accurate approximation is to use an average of the new and old time step (semi-implicit).

During each heat-transfer calculation, the effective buoyancy and mass of the fluid layer changes. Numerical inaccuracies in representing these terms using the current time step (explicit), next time step (implicit) or a combination of these (semi-implicit) leads to differences in the effective buoyancy distribution obtained. For this reason, it was necessary to split the heat-transfer calculation (for each advective time step) into $n_{\mathrm{ht}}$ steps. Using a large number of heat-transfer time steps $\left(n_{\mathrm{ht}}=10^{5}\right)$ to provide a very accurate solution, it was found that each method tended towards the same solution exponentially, with the semi-implicit method requiring significantly fewer heat-transfer steps for a given level of accuracy. However, both the implicit and the semi-implicit methods require significantly more numerical effort to complete each heat-transfer calculation than the explicit method.

For the full-scale experimental configurations presented in this paper, it was found that for a numerical accuracy of $0.005 \mathrm{~K}$, the semi-implicit method and the explicit method required 11 and 74 intermediate heat-transfer time steps respectively. Due to the extra numerical effort required to compute the semi-implicit solutions, each simulation took approximately the same length of time for this level of accuracy. In this case, an 8-h simulation took approximately $130 \mathrm{~s}$ on a modest Intel Celeron $1.4 \mathrm{GHz}$ desktop computer.

In these numerical experiments, and indeed in computing the results presented in this paper, 19 ceiling layers were used. This ensured that the numerical inaccuracies associated with calculating the heat transfers through the ceiling were an order of magnitude less than the numerical inaccuracies associated with the heat transfer between the air and the ceiling [15]. Given the level of experimental accuracy in the temperature measurements $( \pm 0.15 \mathrm{~K})$, we shall proceed by discussing the explicit method. See Ref. [15] for details of the implicit and semi-implicit methods.

\subsection{Numerical solution}

Using the explicit method, substituting the temporal and spatial gradients using Eq. (10), Eq. (4) may be written:

$\frac{\rho_{\mathrm{a}} c_{\mathrm{p}, \mathrm{a}} A\left(H_{\mathrm{r}, \mathrm{eff}}-Z_{n-1}^{p}\right)}{\Delta t}\left(\delta_{n}^{p+1}-\delta_{n}^{p}\right)=\alpha_{\mathrm{conv}, \mathrm{ci}} A\left(\delta_{\mathrm{c}, 1}^{p}-\delta_{n}^{p}\right)$,

which can be written in terms of $\delta_{n}^{p+1}$ by suitable rearranging, and simplified using the appropriate non-dimensional parameters:

$\delta_{n}^{p+1}=\left(1-S t_{\mathrm{ci}} \frac{\Delta \tau}{1-z_{n-1}^{p}}\right) \delta_{n}^{p}+S t_{\mathrm{ci}} \frac{\Delta \tau}{1-z_{n-1}^{p}} \delta_{\mathrm{c}, 1}^{p}$,

where $S t$ is the Stanton number obtained by setting the velocity scale equal to the ratio of the effective room height and the fillingbox time scale (from Eq. (2)):

$S t=\frac{\alpha_{\text {conv }} t_{\mathrm{s}}}{\rho c_{\mathrm{p}} H_{\mathrm{r}, \mathrm{eff}}}$.

Similarly, Eq. (5) may be written:

$$
\begin{aligned}
\frac{\rho_{\mathrm{a}} c_{\mathrm{p}, \mathrm{a}} A \Delta Z}{2 \Delta t}\left(\delta_{\mathrm{c}, 1}^{p+1}-\delta_{\mathrm{c}, 1}^{p}\right)= & \alpha_{\mathrm{conv}, \mathrm{ci}} A\left(\delta_{n}^{p}-\delta_{\mathrm{c}, 1}^{p}\right)+\frac{k_{\mathrm{c}} A}{\Delta Z} \\
& \left(\delta_{\mathrm{c}, 2}^{p}-\delta_{\mathrm{c}, 1}^{p}\right)-\alpha_{\mathrm{rad}} A\left(\delta_{\mathrm{c}, 1}^{p}-\delta_{\mathrm{f}}^{p}\right),
\end{aligned}
$$

and simplified using appropriate non-dimensional parameters:

$$
\begin{aligned}
\delta_{\mathrm{c}, 1}^{p+1}= & \left(1-2 F o_{\mathrm{c}}\left(B i_{\mathrm{ci}}+\widetilde{B} i_{\mathrm{c}}+1\right)\right) \delta_{\mathrm{c}, 1}^{p} \\
& +2 F o_{\mathrm{c}}\left(B i_{\mathrm{ci}} \delta_{n}^{p}+\widetilde{B} i_{\mathrm{c}} \delta_{\mathrm{f}}^{p}+\delta_{\mathrm{c}, 2}^{p}\right),
\end{aligned}
$$

where $B i_{\mathrm{ci}}$ and $F o_{\mathrm{c}}$ are the Biot and the Fourier number respectively and $\widetilde{B} i_{\mathrm{c}}$ is a form of the Biot number based on the radiative heattransfer coefficient:

$$
B i=\frac{\alpha_{\mathrm{conv}} L_{\mathrm{s}}}{k}, \widetilde{B} \boldsymbol{i}=\frac{\alpha_{\mathrm{rad}} L_{\mathrm{s}}}{k} \text { and } F o=\frac{\widehat{\alpha} \Delta t}{L_{\mathrm{s}}^{2}},
$$


where $L_{\mathrm{S}}=\Delta Z$ for the ceiling and $L_{\mathrm{S}}=L_{\mathrm{f}}$ for the floor. Similarly, it is possible to obtain an explicit form of Eqs. (6)-(9):

$$
\begin{aligned}
\delta_{\mathrm{c}, j}^{p+1}= & \left(1-2 F o_{\mathrm{c}}\right) \delta_{c, j}^{p}+F o_{\mathrm{c}}\left(\delta_{\mathrm{c}, j-1}^{p}+\delta_{\mathrm{c}, j+1}^{p}\right), \\
\delta_{\mathrm{c}, n_{\mathrm{T}}}^{p+1}= & \left(1-2 F o_{\mathrm{c}}\left(1+B i_{\mathrm{cr}}\right)\right) \delta_{\mathrm{c}, n_{\mathrm{T}}}^{p}+2 F o_{\mathrm{c}}\left(B i_{\mathrm{cr}} \delta_{\mathrm{o}}^{p}+\delta_{n_{\mathrm{T}}-1}^{p}\right), \\
\delta_{\mathrm{f}}^{p+1}= & \left(1-2 F o_{\mathrm{f}}\left(B i_{\mathrm{f}}+\widetilde{B} i_{\mathrm{f}}+1\right)\right) \delta_{\mathrm{f}}^{p} \\
& +2 F o_{\mathrm{f}}\left(B i_{\mathrm{f}} \delta_{1}^{p}+\widetilde{B} i_{\mathrm{f}} \delta_{\mathrm{c}, 1}^{p}+\delta_{\mathrm{o}}^{p}\right), \\
\delta_{1}^{p+1}= & \left(1-\frac{\Delta \tau}{z_{1}^{p}-z_{\mathrm{f}}}\left(S t_{\mathrm{f}}+q_{\mathrm{v}}\right)\right) \delta_{1}^{p}+\frac{\Delta \tau}{z_{1}^{p}-z_{\mathrm{f}}}\left(S t_{\mathrm{f}} \delta_{\mathrm{f}}^{p}+q_{\mathrm{v}} \delta_{\mathrm{o}}^{p}\right),
\end{aligned}
$$

where the buoyancy of the fluid outside remains constant $\left(\delta_{\mathrm{o}}^{p+1}=\delta_{\mathrm{o}}^{p}\right)$.

There are very few empirical measurements of the convective heat-transfer coefficient in rooms ventilated by displacement ventilation. Novoselac et al. [16] obtained a correlation for forced displacement ventilation concentrating on heat transfer at the floor. Their correlation for surfaces that are hotter than the surrounding air is reproduced here. We present a form of this equation where temperatures are written in terms of effective buoyancy, and the ventilation flow rate is non-dimensionalised. This results in a number of additional terms (contained in square brackets); however, for a given configuration, these extra terms are constant. The correlation incorporates a new representation for forced convection, together with an existing correlation for free convection (proposed by Awbi and Hatton [17]). These correlation coefficients are:

$\alpha_{\text {conv,free }}=\frac{2.175}{D_{\mathrm{h}}^{0.076}}\left[\frac{g_{\mathrm{s}}^{\prime} T_{\mathrm{o}}}{g}\right]^{0.308}\left(\delta_{\text {sur }}-\delta_{\text {air }}\right)^{0.308}$,

for free convection and:

$\alpha_{\text {conv,forced }}=0.48\left[\frac{3600}{t_{\mathrm{s}}}\right]^{0.8} \frac{\left|\delta_{\text {sur }}-\delta_{\mathrm{o}}\right|}{\left(\delta_{\text {sur }}-\delta_{\text {air }}\right)} q_{\mathrm{v}}^{0.8}$,

for forced convection, where $\delta_{\text {sur }}$ and $\delta_{\text {air }}$ are the effective buoyancy of the surface and the air respectively, and $D_{\mathrm{h}}$ is the hydraulic diameter of the surface. In the original paper, the ventilation flow rate was defined in terms of room volumes per hour, hence the 3600 term in Eq. (19). The total convection coefficient is then calculated as:

$\alpha_{\text {conv }, \text { tot }}=\left(\alpha_{\text {conv,free }}^{6}+\alpha_{\text {conv, forced }}^{6}\right)^{1 / 6}$.

In this paper, we use this correlation to evaluate the convection coefficient of the floor (free and forced) and the outside ceiling surface (free). For the floor $\delta_{\text {sur }}=\delta_{\mathrm{f}}$ and $\delta_{\text {air }}=\delta_{1}$; for the outside ceiling surface $\delta_{\mathrm{sur}}=\delta_{\mathrm{c}, n_{\mathrm{T}}}$ and $\delta_{\text {air }}=\delta_{\mathrm{o}}$. Although the convection coefficient varies as a function of time, typical values obtained using this correlation (Eq. (20)) are $3 \mathrm{~W} \mathrm{~m}^{-2} \mathrm{~K}^{-1}$ for the outside ceiling and $2.5 \mathrm{~W} \mathrm{~m}^{-2} \mathrm{~K}^{-1}$ for the floor (see Appendix).

However, in their paper they suggest the use of this correlation for ceiling surfaces, ignoring forced convection due to local advective flows. In our study, the flow that impinges on the ceiling produces a turbulent gravity-driven flow, significantly forcing convective heat transfer. For this reason we have used a constant based on temperature measurements obtained close to and on the ceiling surfaces. This was evaluated to be 38 and $46 \mathrm{~W} \mathrm{~m}^{-2} \mathrm{~K}^{-1}$ and so we used the average $\left(42 \mathrm{~W} \mathrm{~m}^{-2} \mathrm{~K}^{-1}\right)$ for all simulations conducted.

Using a linear form of the Stefan-Boltzmann law, the radiative heat-transfer coefficient is dependent on the temperature, the Stefan-Boltzmann constant $\left(\sigma=5.67 \times 10^{-8} \mathrm{~W} \mathrm{~m}^{-2} \mathrm{~K}^{-4}\right)$ and emissivity $(\varepsilon)$ :

$\alpha_{\text {rad }}=4 \sigma \varepsilon T^{3}$,

and so, assuming an emissivity value of 0.9 , the radiative heattransfer coefficient at $300 \mathrm{~K}$ is $5.5 \mathrm{~W} \mathrm{~m}^{-2} \mathrm{~K}^{-1}$. In the experiments conducted here, this varies by only $\sim 3 \%$. To assess the effectiveness of this model, the experiments described in Section 2 will be compared with these mathematical-modelling predictions in the following sections.

\section{Results}

In this section, we compare the results obtained using the mathematical model presented in Section 3, the experiments described in Section 2, and existing adiabatic mathematical models for buoyancy-driven ventilation. In Section 4.1, the new model is compared directly with the experimental results. The vertical temperature profile and ventilation flow rate are presented as a function of time. In Section 4.2, a comparison between these results and adiabatic models $[9,10]$ is given.

\subsection{Comparison with experiments}

\subsubsection{Thermal stratification}

The measured and predicted (using the new mathematical model) vertical temperature profiles for displacement and doorway ventilation are presented in Figs. 3 and 4 respectively. The results are presented in terms of the temperature difference between the air inside and outside the room for $t=3,30,60$ and 480 min using two heat-source configurations.

The experimental results show that there is a diffuse yet discernible stratification interface between the cooler air in the lower part of the room and the warmer air in the upper part of the room in most cases (see Figs. 3 and 4). This two-layer profile is observed typically within one hour from the start of each experiment and persists for the duration of the experiment, with the overall temperature increasing with time. For the displacementventilation experiments, the two-layer stratification is more prominent in the results obtained using two rings and smaller $a^{*}$. Furthermore, as $a^{*}$ is increased, the stratification interface becomes more diffuse for both source conditions. This is possibly due to increased mixing at the stratification interface associated with larger ventilation flow rates $\left(Q_{\mathrm{V}} \propto a^{*}\right)$.

A gravity current produced by the plume impinging on the ceiling is evident in the measured temperature results. The temperature in this region is typically $0.5 \mathrm{~K}$ higher than the surrounding air, and it is estimated that the depth of the gravity current is approximately $40 \mathrm{~cm}\left(\approx 0.144 H_{\mathrm{r}}\right.$; similar in size to that observed in reduced-scale experiments in non-dimensional terms [1]). Close to the floor a similar flow can be seen, where the temperature varies in much the same way (although now in the opposite sense), and the depth of this flow is similar in magnitude to the ceiling flow.

Using temperature measurements obtained at the inlet, it was found that the temperature of the air flowing into the room increased during each experiment. The increase was typically less than $1.0 \mathrm{~K}$ over the course of each 8-h experiment. This was caused by an overall increase in the temperature of the air outside the chamber due to the ventilation flow. 

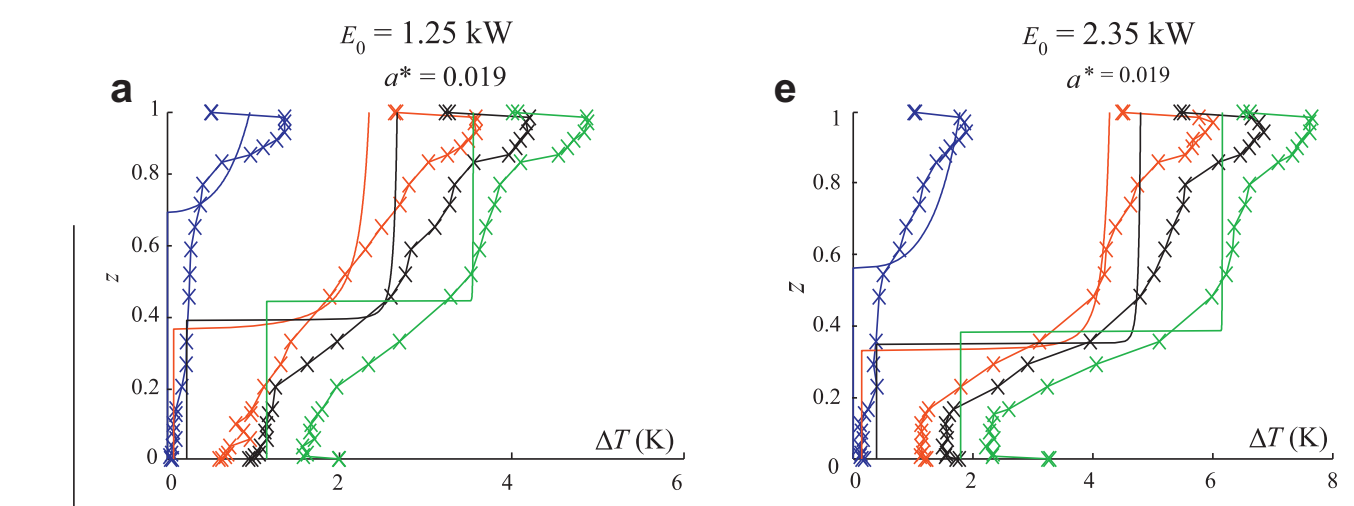

b $\quad a^{*}=0.030$

f
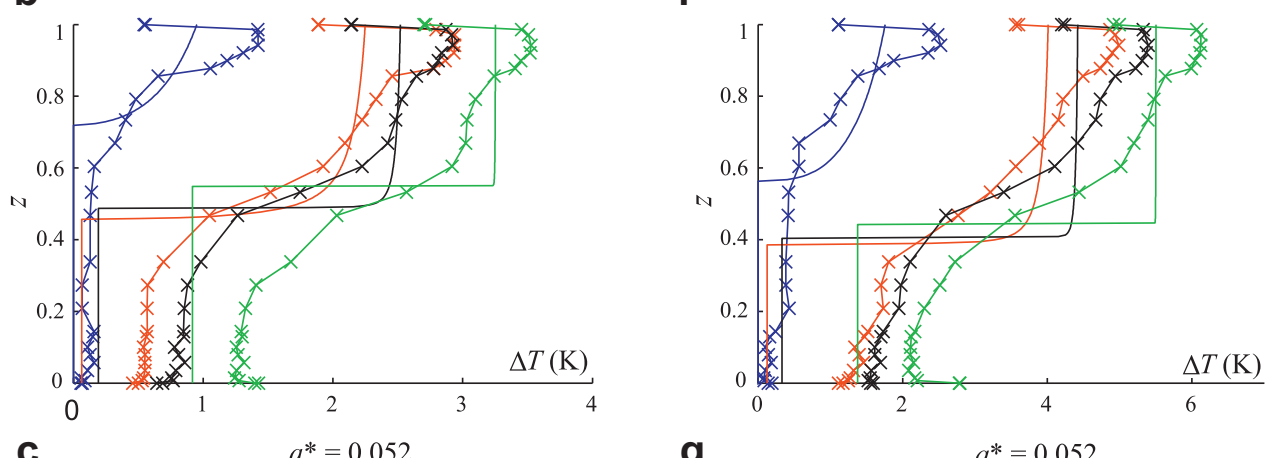

C
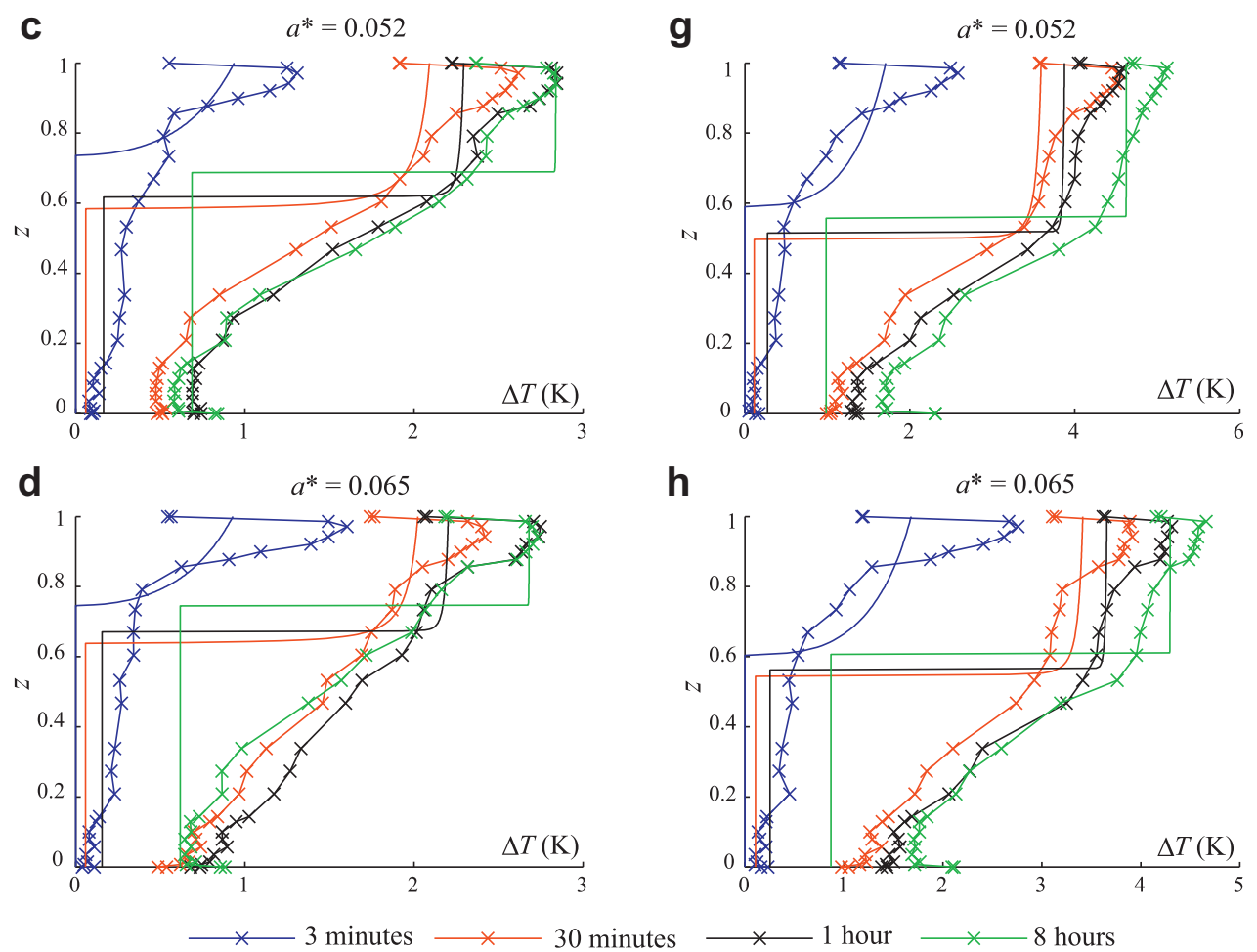

Fig. 3. The vertical stratification of temperature for a room ventilated by a displacement ventilation. Modelled and measured results are presented for $t=3$, 30 and 60 min and $8 \mathrm{~h}$.

Comparing the measured and predicted vertical temperature profiles, there is generally a very good agreement (Figs. 3 and 4). In most cases, the mathematical model under-predicts the temperature (more significantly in the lower layer) and this is perhaps largely to do with the increase in temperature of the air flowing into the room during the experiments (not accounted for in the analysis of the experimental results). In terms of the overall stratification, the distinction between the upper and the lower layer is clearly visible in the model results, as there is a sharp stratification interface between the upper and lower layers. This is not as clear in the experimental results, although a diffuse stratification interface is discernible in most cases.

4.1.2. Volume flow rate and velocity measurements

Speed measurements were obtained during both sets of experiments. In the displacement-ventilation experiments, these 

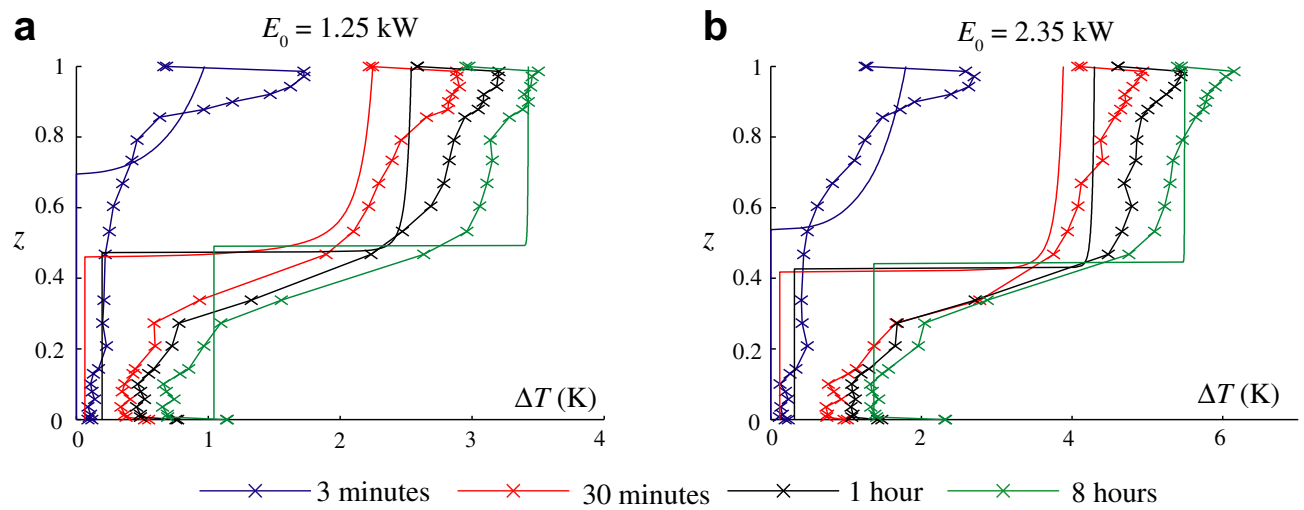

Fig. 4. The vertical stratification of temperature for a room ventilated by a single doorway. Modelled and measured results are presented for $t=3$ min (blue lines), 30 min (red lines), $1 \mathrm{~h}$ (black lines) and $8 \mathrm{~h}$ (green lines).

were used to calculate the ventilation flow rate. In the doorway experiments, these were used to investigate the doorway velocity profile. In this section, both sets of results are presented and are compared with the mathematical-modelling results.

In Fig. 5, the predicted and the measured ventilation flow rates are compared. There is a reasonably good fit, with the error between the mathematical model and the experimental results being less than $20 \%$. In most cases the mathematical model underpredicts the volume flow rate; this is not surprising given the vertical temperature stratification results (see Fig. 3). For naturally ventilated spaces, it is the hydrostatic head that drives the flow, and this is proportional to the integrated temperature difference $\left(\propto \int \Delta T \mathrm{~d} z\right.$ ). Based on the stratification results (Fig. 3), it can be seen that the hydrostatic head is greater in the experiments than in the mathematical model, accounting for the differences in flow rate between the experiments and the mathematical model.

In Fig. 6, the measured and modelled velocity profile are presented. These results assume that the flow was perpendicular to the doorway opening, assigning a positive value for outflow and a negative value for inflow. This was straightforward for the flow close to the top and bottom of the door, as the flow there is outward and inward respectively. However, close to the interface this was much more difficult, as the device used to measure the flow speed was unable to resolve the flow direction. The direction of the flow in this region was evaluated visually from the general tend.

The velocity data presented here is scaled by the source power output $\left(U_{\text {scaled }}=U_{\text {measured }} E_{0}^{-1 / 3}\right)$ and it can be seen that there is good agreement between the experimental results for each source
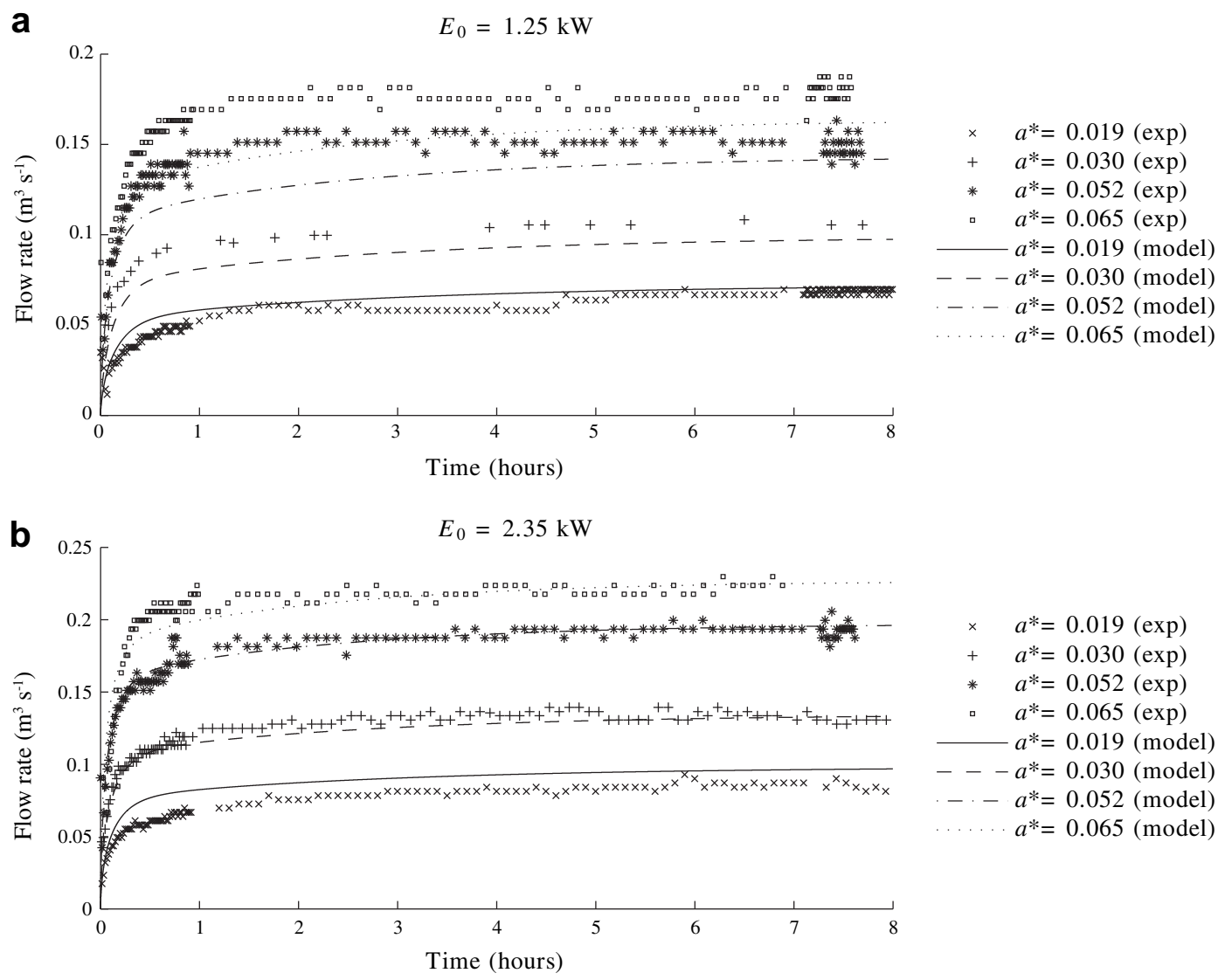

Fig. 5. Measured and predicted ventilation flow rates for various effective opening areas. 


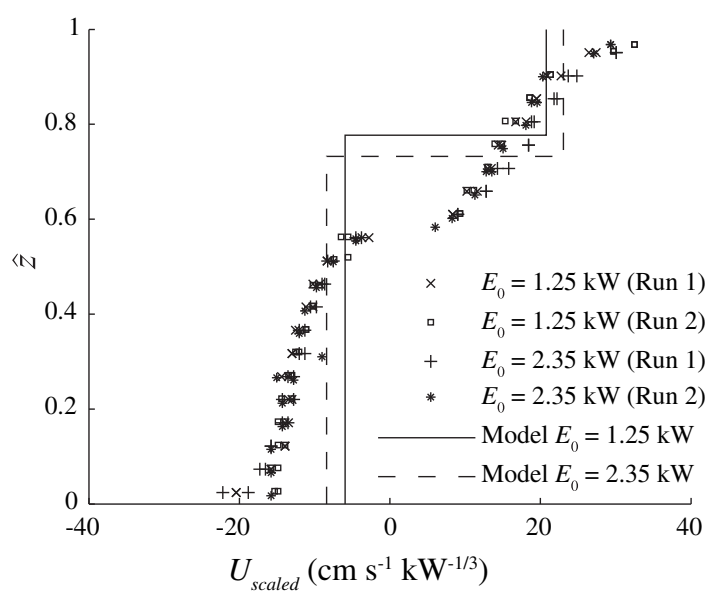

Fig. 6. Velocity profile at the doorway where the velocity has been scaled by the total source power output $\left(U_{\text {scaled }}=U_{\text {measured }} E_{0}^{-1 / 3}\right)$.

condition when scaled in this way. The profile reveals that the velocity in the upper and lower part of the doorway is not uniform (as modelled) and in fact has a tendency to speed up close to the top of the doorway. The location of the exchange interface observed experimentally occurs at approximately $57 \%$ of the doorway height.

The results obtained using the mathematical model are also presented in Fig. 6 and it can be seen that the modelled doorway interface is located at approximately 77 and $73 \%$ of the doorway height for $E_{0}=1.25$ and $2.35 \mathrm{~kW}$ respectively. It can also be seen in Fig. 6 that the magnitude of the velocity in the upper layer is approximately the same as that observed experimentally. However, the same is not true in the lower layer, where the model underpredicts the velocity by a factor of two to three.

These discrepancies are most likely related to the way in which the flow is modelled through the doorway. In the mathematical model, the flow through the doorway is assumed to consist of two layers flowing in opposing directions with a uniform velocity. The model is based on laboratory simulations where saline solution is used to model buoyancy. In these simulations, fluid in the lower

Table 3

Comparison between the temperatures predicted and measured in the upper $\left(\Delta T_{\mathrm{u}}\right)$ and lower $\left(\Delta T_{1}\right)$ layers, relative to the ambient (external) temperature.

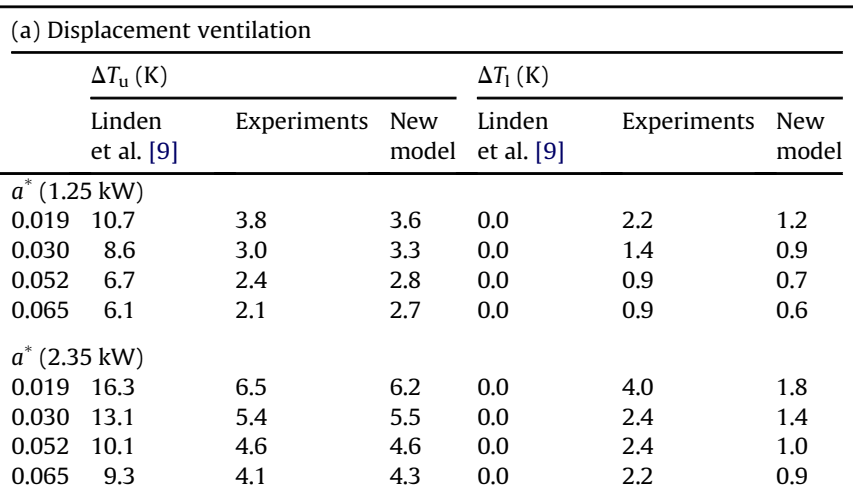

(b) Doorway ventilation

\begin{tabular}{|c|c|c|c|c|c|c|}
\hline & \multicolumn{3}{|l|}{$\Delta T_{\mathrm{u}}(\mathrm{K})$} & \multicolumn{3}{|l|}{$\Delta T_{1}(\mathrm{~K})$} \\
\hline & $\begin{array}{l}\text { Phillips and } \\
\text { Woods [10] }\end{array}$ & Experiments & $\begin{array}{l}\text { New } \\
\text { model }\end{array}$ & $\begin{array}{l}\text { Phillips and } \\
\text { Woods [10] }\end{array}$ & Experiments & $\begin{array}{l}\text { New } \\
\text { model }\end{array}$ \\
\hline \multicolumn{7}{|c|}{ Source power $(\mathrm{kW})$} \\
\hline 1.25 & 9.8 & 3.2 & 3.4 & 0.0 & 1.1 & 1.0 \\
\hline 2.35 & 14.9 & 5.4 & 5.5 & 0.0 & 2.0 & 1.4 \\
\hline
\end{tabular}

layer has the same buoyancy as the fluid that enters the space. In the full-scale experiments, the air in the lower layer becomes warmer. Some of this air (now buoyant with respect to the inflowing air) then exits through the doorway, reducing the interface location at the doorway and increasing the ventilation flow rate.

Having compared the results obtained from both experiments and mathematical models, we shall summarise these findings and show that there is significant improvement in terms of the predicted temperature when the new mathematical model is used as compared to adiabatic models.

\subsection{Comparison with adiabatic models}

It is difficult to directly compare results obtained in salinitydriven and thermally driven experiments due to inherent differences associated with the heat transfer at the boundaries [15]. To illustrate this, a comparison between the steady-state mathematical models $[9,10]$, the new transient-displacement model, and the experimental results is presented in Table 3 for (a) displacement ventilation and (b) doorway ventilation. The results are presented in terms of the temperature difference (between the air inside and outside the room) in the upper $\left(\Delta T_{\mathrm{u}}\right)$ and lower $\left(\Delta T_{1}\right)$ part of the room once the flow had reached steady-state. For the experimental results, a value was selected at $75 \%$ and $25 \%$ of the overall room height to represent the temperature in the upper and lower layers respectively.

The steady-state mathematical models $[9,10]$ over-predict the measured temperature in the upper part of the room by a factor of two to three. In the lower part of the room, the steady-state models assume the temperature difference is zero. As such, none of the effects of thermal redistribution of energy clearly evident in the full-scale experimental results are captured $\left(\Delta T_{1} \neq 0 \mathrm{~K}\right)$. These differences are a result of ignoring the effect of heat transfer at the boundaries. In the new model, some of these processes have been included, and it can be seen that there is a significantly improved agreement when comparing the full-scale experimental results with the new mathematical model.

In the upper part of the room, the error between the new mathematical model and experimental results is typically less than $10 \%$, significantly less than models that do not include heat transfer. In the lower part of the room, the mathematical model typically under-predicts the measured temperature by a factor of two. However, the steady-state model does not include these effects at all, and our new model is clearly an improvement when heattransfer modelling is included.

\section{Summary and conclusions}

A new mathematical model for buoyancy-driven ventilation [1] was modified to include heat transfer at the ceiling and floor. The model was assessed using results obtained from experiments conducted in a full-scale test room, where buoyancy was introduced using a twin-hob heat source.

Heat transfer was modelled using Newton's law of cooling for convective heat transfer between the air and the solid boundaries, Fourier's law for conductive heat transfer through the floor and ceiling, and a linear version of the Stefan-Boltzmann law for radiative heat transfer between the ceiling and floor. Since heat transfer from the walls was small ( $\sim 5 \%$ of the total load), only heat transfer at and between the ceiling and floor was modelled. For other room configurations and materials, the heat transfers through the walls may be more important. However, rooms where the height is the smallest dimension, and where the total heat losses through the ceiling are greater than those through the walls are very common. 
In the experiments, a twin-hob heat source was located at the floor level in the centre of the test room. In most cases, a two-layer stratification in temperature was obtained typically within one hour from the start of each experiment, with the mean room temperature increasing in time. The temperature measurements indicate the presence of a gravity-driven flow on both the ceiling and the floor, with the depth of the gravity current approximately $14 \%$ of the room height.

To assess the model effectiveness, a comparison between the model and the experiments was presented. Given the approximations made here, there was good agreement between the predicted and the measured results. In most cases the mathematical model under-predicts the temperature (more significantly in the lower layer), and it was commented that this is perhaps largely to do with the increase in temperature of the air flowing into the room during the experiments.

Comparison between the experiments, the new mathematical model and steady-state adiabatic mathematical models $[9,10]$ revealed that substantially improved temperature predictions were achieved when the heat-transfer calculation was performed. This illustrates the need to include heat transfer when modelling thermally driven flows.

Using this model, an 8-h simulation of a single room can be obtained in the order of minutes using a modest desktop computer. This is in contrast with CFD simulations of similar flows that take days [7] to obtain steady-state solutions. The reduced time scale means that simple yet effective evaluation of ventilation strategies can be obtained quickly, while still capturing the most significant heat-transfer mechanisms.

\section{Acknowledgements}

This work was supported by EPSRC grant GR/R69037/01.

\section{Appendix}

For four of the displacement-ventilation configurations considered here, we present the convection coefficient associated with the floor and outside ceiling surfaces (see Fig. A1). The results are presented for the smallest and largest effective areas $\left(a^{*}=0.019\right.$ and 0.065 respectively) and for both heat-source configurations. These results were computed using the empirical correlation proposed by Novoselac et al. [16] (see Eq. (20)) with the effective buoyancy and ventilation flow rate calculated using the new mathematical model.

For the floor, the convection coefficient is made up of free and forced parts and for completeness we include these components also. For the smallest effective opening area, the free convection term is approximately double that of the forced convection term for both source conditions (see Fig. A1a\&b). As a result, the forced term has little influence on the total convective heat transfer in these cases. For the larger effective opening areas, the free and forced terms are approximately equal and so both terms influence the total convection coefficient. However, even in this case the influence of the forced term is not significant. This is due to the way the
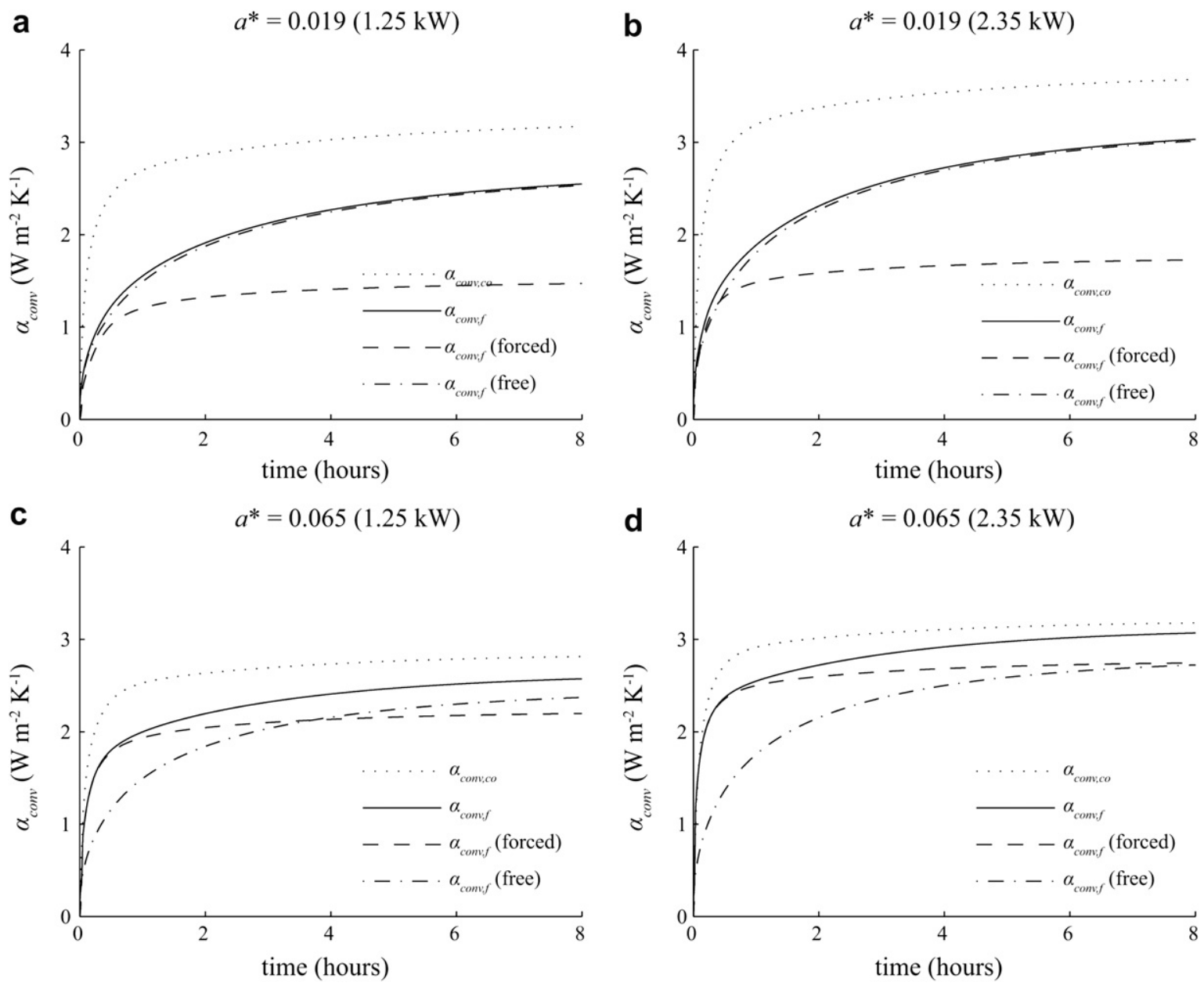

Fig. A1. The convection coefficient as a function of time for four of the experimental configurations considered. 
total convection coefficient is calculated. For example, if the forced and free convection terms are equal to $\alpha_{1}$, then the total $\alpha_{\text {conv,tot }} \approx 1.12 \alpha_{1}$; and where the free convection term is equal to $\alpha_{2}$ and the forced term is $0.5 \alpha_{2}$, the total convection coefficient $\alpha_{\text {conv,tot }} \approx 1.00 \alpha_{2}$.

For the outside ceiling surface, there is no local advective flow and so the forced convection coefficient equals zero. For the experimental configurations considered here, the convective heattransfer coefficient associated with the outside ceiling surface is larger than for the floor. This difference is greater for the experiments with a smaller effective opening area. Finally, although the convection coefficient changes as a function of time (during these calculations), typical values for the outside ceiling surface and the floor are $3 \mathrm{~W} \mathrm{~m}^{-2} \mathrm{~K}^{-1}$ and $2.5 \mathrm{~W} \mathrm{~m}^{-2} \mathrm{~K}^{-1}$ respectively.

\section{References}

[1] Sandbach SD, Lane-Serff GF. Transient buoyancy-driven ventilation: Part 1. Modelling advection. Building and Environment 2011;46(8):1578-88.

[2] Germeles AE. Forced plumes and mixing of liquids in tanks. Journal of Fluid Mechanics 1975;71:601-23.

[3] Heiselberg P, Sandberg M. Convection from a slender cylinder in a ventilated room. In: Proceedings of Roomvent '90, the second international conference on air distribution in rooms, Oslo, Norway; 1990.

[4] Li Y, Sandberg M, Fuchs L. Vertical temperature profiles in rooms ventilated by displacement: full-scale measurement and nodal modelling. Indoor Air 1992;2:225-43.
[5] Li Y, Sandberg M, Fuchs L. Effects of thermal radiation on airflow with displacement ventilation: an experimental investigation. Energy and Buildings 1993;19:263-74.

[6] Howell SA, Potts I. On the natural displacement flow through a full-scale enclosure, and the importance of the radiative participation of the water vapour content of the ambient air. Building and Environment 2002;37:817-23.

[7] Lau J, Chen Q. Floor-supply displacement ventilation for workshops. Building and Environment 2007;42:1718-30.

[8] Bouzinaoui A, Vallette P, Lemoine F, Fontaine JR, Devienne R. Experimental study of thermal stratification in ventilated confined spaces. International Journal of Heat and Mass Transfer 2005;48:4121-31.

[9] Linden PF, Lane-Serff GF, Smeed DA. Emptying filling boxes: the fluid mechanics of natural ventilation. Journal of Fluid Mechanics 1990;212: 309-35.

[10] Phillips JC, Woods AW. On ventilation of a heated room through a single doorway. Building and Environment 2004;39:241-53.

[11] Incropera FP, DeWitt DP. Fundamentals of heat and mass transfer. 4th ed. John Wiley and Sons; 1996.

[12] Worster MG, Huppert HE. Time-dependent density profiles in a filling box. Journal of Fluid Mechanics 1983:132:457-66.

[13] Mundt E. Convection flows in rooms with temperature gradients - theory and measurement. In: Proceedings of Roomvent '92, the third international conference on air distribution in rooms, Aalborg, Denmark; 1992.

[14] Mundt E. Displacement ventilation systems - convection flows and temperature gradients. Building and Environment 1995;30:129-33.

[15] Sandbach SD. Mathematical and laboratory modelling of ventilation. The University of Manchester, PhD thesis; 2009.

[16] Novoselac A, Burley BJ, Srebic J. Development of new and validation of existing convection correlations for rooms with displacement ventilation systems. Energy and Buildings 2006;38:163-73.

[17] Awbi HB, Hatton A. Natural convection from heated room surfaces. Energy and Buildings 1999;30:233-44. 